\title{
Obesity is associated with increased arterial stiffness from adolescence until old age
}

\author{
Pantelis E. Zebekakis ${ }^{a, b}$, Tim Nawrot ${ }^{a}$, Lutgarde Thijs ${ }^{a}$, Elisabeth J. Balkestein ${ }^{c}$, \\ Janneke van der Heijden-Spek ${ }^{c}$, Luc M. Van Bortel ${ }^{d}$, \\ Harry A. Struijker-Boudier ${ }^{\mathrm{c}}$, Michel E. Safar ${ }^{\mathrm{e}}$ and Jan A. Staessen ${ }^{\mathrm{a}}$
}

\begin{abstract}
Objective To our knowledge, only two previous studies have investigated the age dependence of the relationship between the characteristics of large arteries and excessive body weight. We therefore investigated whether the relationship between arterial stiffness and body mass index (BMI) was consistent across an age range from 10 to 86 years.
\end{abstract}

\begin{abstract}
Methods Using a cross-sectional population-based design, we randomly recruited 1306 individuals (median age 43.9 years; $50.5 \%$ women). Using a wall-tracking ultrasound system, we measured the properties of the carotid, femoral and brachial arteries and carotid-femoral pulse wave velocity. We analysed men and women separately while adjusting for significant covariates, including age, mean arterial pressure, heart rate, current smoking, alcohol intake and use of antihypertensive drugs.
\end{abstract}

Results Before and after adjustment, arterial diameter increased with BMI in all territories, with an opposite trend for arterial distensibility. In men and women, the relationships of brachial and femoral properties with BMI were consistent across the whole age range. In men and women, carotid distensibility decreased more with BMI at young than old age. In middle-aged and older women, but not in men of any age, pulse wave velocity increased with higher BMI.

Conclusions Across a wide age range, the diameter and stiffness of muscular arteries increased with higher BMI. In elastic arteries, the relationship between arterial stiffness and BMI was more complex and varied with sex and age. The mechanisms underlying the influence of adiposity on the properties of muscular and elastic arteries and the reversibility of these associations by weight reduction at young age need further clarification. J Hypertens 23:1839-1846 @ 2005 Lippincott Williams \& Wilkins.

\section{Journal of Hypertension 2005, 23:1839-1846}

Keywords: aging, arterial compliance, arterial distensibility, arterial stiffness, body mass index, obesity

${ }^{a}$ The Study Coordinating Centre, Hypertension and Cardiovascular Rehabilitation Unit, Department of Molecular and Cardiovascular Research, University of

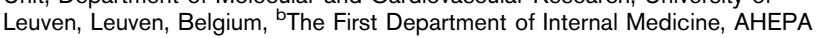
University Hospital, Aristotle University, Thessalonica, Greece, 'The Department of Pharmacology and Toxicology, University of Maastricht, Maastricht, The Netherlands, ${ }^{\mathrm{d}}$ The Heymans Institute of Pharmacology, University of Gent, Gent, Belgium and ${ }^{\mathrm{e} T h e}$ Hypertension Unit, Centre for Diagnosis, Hôtel-Dieu Hospital, Paris, France.

Sponsorship: The European Union (IC15-CT98-0329-EPOGH and QLGI-CT2000-01137-EURNETGEN), the Fonds voor Wetenschappelijk Onderzoek Vlaanderen, Brussels, Belgium (G.0291.98, G.0424.03 and G.0256.05), and the University of Leuven, Belgium (OT/99/28 and OT/04/34) provided research grants in support of the FLEMENGHO study.

Correspondence and requests for reprints to Jan A. Staessen, MD, PhD, Studiecoördnatiecentrum, Laboratorium Hypertensie, Campus Gasthuisberg Herestraat 49, postbus 702, B-3000 Leuven, Belgium. Tel: +32 1634 7104; fax: +32 16347106 e-mail: jan.staessen@med.kuleuven.be

Received 2 February 2005 Revised 16 June 2005 Accepted 17 June 2005

See editorial commentary page 1789

\section{Introduction}

Worldwide, the prevalence of overweight and obesity has reached pandemic proportions [1,2]. In the United States and western Europe, adiposity substantially adds to the cardiovascular risk of $60 \%$ of adults and $10 \%$ of youth. Obesity is associated with impaired function of the large arteries, which might be the consequence of metabolic dysregulation, inflammatory pathways, obstructive sleep apnoea, or other mechanisms [3,4]. However, to our knowledge, only two previous studies $[5,6]$ have investigated the age dependence of the relationship between the characteristics of the large arteries and excessive body weight. In a cross-sectional study of 363 adults aged
20-77 years, Wildman and colleagues [6], while adjusting for age and other confounders, noticed positive associations between aortic pulse wave velocity and various measures of obesity. In a prospective study of 159 pubertal adolescents followed up for over 20 years and in a cross-sectional analysis of 336 subjects aged 36 years, Ferreira and coworkers [5] found that the stiffness of several large arteries increased with obesity.

In the framework of the Flemish Study on Environment, Genes and Health Outcomes (FLEMENGHO), we used the same ultrasound technique as in the study by Ferreira et al. [5] to collect complex vascular phenotypes in 1306 
individuals with a wide age range, who were randomly recruited from the population [7]. Here, we report the combined influences of body mass index (BMI) and age on vascular structure and function.

\section{Methods}

\section{Study population}

The FLEMENGHO study [7] involves a random sample of families living in a defined geographical area in northern Belgium. Eligible offspring were at least 10 years old. The Ethics Committee of the University of Leuven approved the study. All participants or their parents gave informed written consent. The participation rate averaged $64.3 \%$.

\section{Clinical measurements}

For at least $3 \mathrm{~h}$ before being examined, the participants refrained from heavy exercise, smoking, alcohol or caffeine-containing beverages. Trained nurses measured blood pressure and anthropometric characteristics. They administered a questionnaire to collect information about each subject's medical history, smoking and drinking habits, and intake of medications. Each participant's office blood pressure was the average of five consecutive readings. BMI was defined as weight in kilograms divided by the square of height in metres. Normal weight, overweight and obesity corresponded with ranges of BMI of less than $25 \mathrm{~kg} / \mathrm{m}^{2}, 25-30 \mathrm{~kg} / \mathrm{m}^{2}$ and $30 \mathrm{~kg} / \mathrm{m}^{2}$ or greater, respectively. We measured blood glucose and total and high-density lipoprotein (HDL)-cholesterol on a venous blood sample by standard biochemical methods.

\section{Vascular measurements}

By means of a pulsed ultrasound wall-tracking system (Wall Track System; Pie Medical, Maastricht, the Netherlands), three trained researchers (E.J.B., J.J.H-S., and T.N.) obtained vascular measurements at the common carotid artery $2 \mathrm{~cm}$ proximal of the carotid bulb, at the femoral artery $1 \mathrm{~cm}$ proximal of the bifurcation into the profound and superficial branches, and at the right brachial artery $2 \mathrm{~cm}$ proximal of the antecubital fossa [7]. The observers also determined carotid-femoral pulse wave velocity from the length of the carotid-femoral segment and the transit time of the pulse wave. The carotid-femoral segment was the difference of the distances between the site of the carotid ultrasound measurement and the suprasternal notch and between the suprasternal notch and the site of the femoral measurement.

During the ultrasound examination, an automated oscillometric device (Dinamap 845; Critikon Inc., Tampa, Florida, USA) recorded blood pressure at the upper arm at 5-min intervals. As for the conventional auscultatory measurements, cuff size was adjusted to the circumference of the upper arm [8]. Standard cuffs had an inflatable bladder of $12 \mathrm{~cm} \times 24 \mathrm{~cm}$. If the arm circumference exceeded $31 \mathrm{~cm}$, larger cuffs with a bladder of $15 \mathrm{~cm}$ $\times 35 \mathrm{~cm}$ were utilized. As described elsewhere [9], the observers applied applanation tonometry with a pencilshaped probe (Millar Instruments Inc., Houston, Texas, USA) and calibration to mean and diastolic pressure at the brachial artery to derive the local pulse pressure at the other arteries. We computed cross-sectional compliance (CC) and the distensibility coefficient (DC) from the diastolic cross-sectional area (A), the systolic increase in cross-sectional area $(\Delta \mathrm{A})$ and the local pulse pressure $(\Delta \mathrm{P})$ [10]: $\mathrm{CC}=\Delta \mathrm{A} / \Delta \mathrm{P}$ and $\mathrm{DC}=(\Delta \mathrm{A} / \mathrm{A}) / \Delta \mathrm{P} . \mathrm{A}$ and $\Delta \mathrm{A}$ were calculated as $\mathrm{A}=\pi \times(\mathrm{D} / 2)^{2}$ and $\Delta \mathrm{A}=\pi \times$ $[(\mathrm{D}+\Delta \mathrm{D}) / 2]^{2}-\pi \times(\mathrm{D} / 2)^{2}$.

\section{Statistical analysis}

For database management and statistical analysis, we used SAS software version 8.2 (SAS Institute Inc., Cary, North Carolina, USA). We analysed women and men separately. We compared means, medians and proportions by means of a large sample z-test, Wilcoxon's test and the $\chi^{2}$ statistic, respectively. Our statistical methods also included single and multiple linear regression. For the clarity of presentation and to allow comparison with other reports [6], we subdivided participants according to median age. However, we only used continuous distributions to explore the interaction between BMI and age in relation to the vascular properties.

Significant covariates of the vascular measurements were traced by a stepwise regression procedure, terminating when all partial regression coefficients were significant at $5 \%$. Covariates considered for entry into the model were observer, age, BMI, pulse rate, mean arterial pressure, current smoking, alcohol intake and the use of antihypertensive drugs. In sensitivity analyses, we forced additional covariates in the models, including blood glucose and serum total and HDLcholesterol, and in women also the use of oral contraceptives and hormonal replacement therapy. We also repeated the analyses with patients on antihypertensive treatment excluded.

\section{Results}

\section{Characteristics of participants}

The median age of the 1306 participants, 646 men and 660 women, was 43.9 years (range $10-86$ years). Table 1 summarizes their demographic characteristics. In smokers, median tobacco use was 18 cigarettes a day (10th to 90th percentile interval, 6-30). In drinkers, median alcohol consumption was $20 \mathrm{~g}$ a day $(10-50 \mathrm{~g})$. Among 412 premenopausal and 248 postmenopausal women, $76(18.5 \%)$ and $13(5.2 \%)$ used oral contraceptives or hormonal replacement therapy, respectively.

\section{Vessel wall properties in relation to body mass index}

Table 2 gives the vessel wall properties by sex and vascular territory. Figure 1 illustrates the association 
Table 1 Characteristics of participants by sex

\begin{tabular}{lcc}
\hline Variable name & Women $(n=660)$ & Men $(n=646)$ \\
\hline Demographic characteristics & & \\
Age (years) & $44.2 \pm 15.8$ & $44.9 \pm 15.4$ \\
Body mass index $\left(\mathrm{kg} / \mathrm{m}^{2}\right)$ & $24.9 \pm 4.6$ & $25.7 \pm 3.8$ \\
Systolic pressure $(\mathrm{mmHg})^{\mathrm{a}}$ & $117.7 \pm 14.8$ & $125.2 \pm 13.1$ \\
Diastolic pressure $(\mathrm{mmHg})^{\mathrm{a}}$ & $70.4 \pm 8.9$ & $74.3 \pm 8.9$ \\
Pulse rate (beats per minute) & $64.3 \pm 9.1$ & $60.3 \pm 10.0$ \\
Numbers with characteristics $(\%)$ & & \\
Body mass index $25-30 \mathrm{~kg} / \mathrm{m}^{2}$ & $185(28.0)$ & $296(45.8)$ \\
Body mass index $\geq 30 \mathrm{~kg} / \mathrm{m}^{2}$ & $93(14.0)$ & $80(12.4)$ \\
Smokers & $202(31.3)$ & $180(27.3)$ \\
Drinkers & $196(29.7)$ & $362(56.0)$ \\
Antihypertensive therapy & $95(14.4)$ & $86(13.3)$ \\
Biochemical measurements & & \\
Glucose (mmol/l) & $5.34 \pm 1.22$ & $5.47 \pm 1.70$ \\
Cholesterol total $(\mathrm{mmol} / \mathrm{l})$ & $5.33 \pm 1.06$ & $5.32 \pm 1.06$ \\
HDL-cholesterol $(\mathrm{mmol} / \mathrm{l})$ & $1.64 \pm 0.42$ & $1.31 \pm 0.35$ \\
\end{tabular}

Unless indicated otherwise, values are means \pm SD. Sex differences were sig nificant $(P<0.01)$ with exception of age $(P=0.46)$, current smoking $(P=0.11)$, use of antihypertensive drugs $(P=0.57)$, blood glucose $(P=0.15)$, and total cholesterol $(P=0.91)$. a Average of five auscultatory readings at the brachial artery obtained at the examination centre. HDL, high-density lipoprotein.

between carotid, brachial and femoral diameter and BMI across sex and age group-specific quartiles of the distribution of BMI. Similar information for the distensibility coefficients appears in Figure 2.

Before (Fig. 1) and after adjustment for observer, age, mean arterial pressure, pulse rate, current smoking, alcohol intake and the use of antihypertensive drugs, arterial diameter significantly increased with $\mathrm{BMI}$ in the three vascular territories in women as well as in men (Table 3). Arterial distensibility consistently decreased with BMI (Table 3). With similar adjustments applied, the carotid-femoral pulse wave velocity increased with higher BMI in women, but not in men (Table 3).

Table 2 Arterial wall properties by sex

\begin{tabular}{lcc}
\hline Variable name & $\begin{array}{c}\text { Women } \\
(n=660)\end{array}$ & $\begin{array}{c}\text { Men } \\
(n=646)\end{array}$ \\
\hline Carotid-femoral pulse wave velocity $(\mathrm{m} / \mathrm{s})$ & $6.31 \pm 2.09$ & $6.56 \pm 2.09$ \\
Common carotid artery & & \\
Diameter $(\mathrm{mm})$ & $6.83 \pm 0.81$ & $7.58 \pm 0.94$ \\
Distension $(\mu \mathrm{m})$ & $491.5 \pm 191.9$ & $537.8 \pm 208.2$ \\
Pulse pressure $(\mathrm{mmHg})$ & $46.7 \pm 12.3$ & $49.2 \pm 13.3$ \\
Distensibility coefficient $\left(10^{-3} / \mathrm{kPa}\right)$ & $26.7 \pm 14.1$ & $24.2 \pm 11.9$ \\
Compliance coefficient $\left(\mathrm{mm}^{2} / \mathrm{kPa}\right)$ & $0.95 \pm 0.44$ & $1.06 \pm 0.45$ \\
Brachial artery & & \\
Diameter $(\mathrm{mm})$ & $3.90 \pm 0.71$ & $4.80 \pm 0.72$ \\
Distension $(\mu \mathrm{m})$ & $154.2 \pm 116.4$ & $175.5 \pm 126.7$ \\
Pulse pressure $(\mathrm{mmHg})$ & $47.1 \pm 10.0$ & $50.6 \pm 10.2$ \\
Distensibility coefficient $\left(10^{-3} / \mathrm{kPa}\right)$ & $13.8 \pm 12.0$ & $12.1 \pm 12.0$ \\
Compliance coefficient $\left(\mathrm{mm}^{2} / \mathrm{kPa}\right)$ & $0.15 \pm 0.12$ & $0.20 \pm 0.15$ \\
Femoral artery & & \\
Diameter $(\mathrm{mm})$ & $8.50 \pm 1.16$ & $9.94 \pm 1.46$ \\
Distension $(\mu \mathrm{m})$ & $290.5 \pm 148.2$ & $312.4 \pm 185.0$ \\
Pulse pressure $(\mathrm{mmHg})$ & $50.8 \pm 13.0$ & $54.4 \pm 13.2$ \\
Distensibility coefficient $\left(10^{-3} / \mathrm{kPa}\right)$ & $11.5 \pm 7.3$ & $9.5 \pm 6.0$ \\
Cross-sectional compliance $(\mathrm{mm} / \mathrm{kPa})$ & $0.63 \pm 0.38$ & $0.73 \pm 0.47$ \\
\hline
\end{tabular}

Values are means \pm SD. All sex differences were statistically significant $(P<0.02)$
Fig. 1

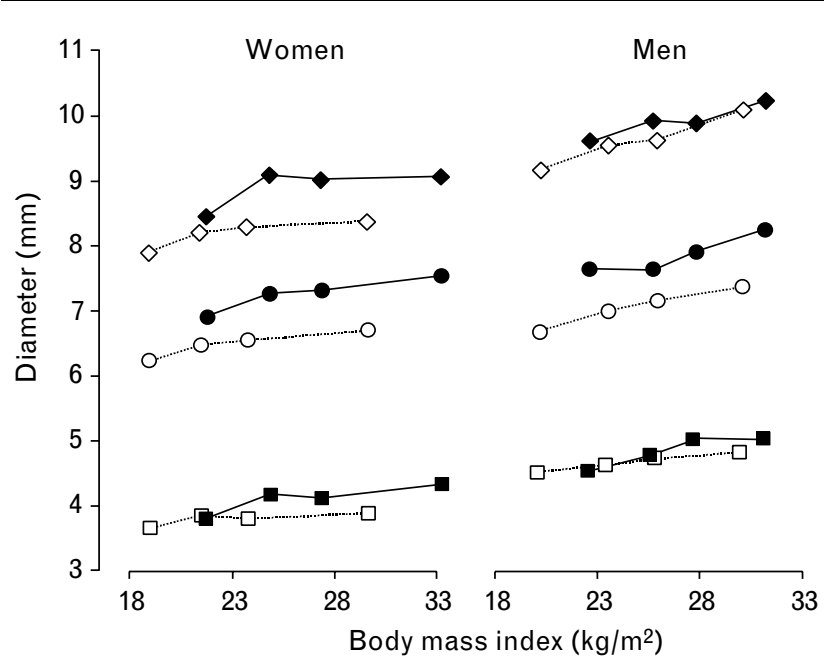

Arterial diameter by sex and vascular territory. Plotted values are means in sex and age group-specific quartiles of body mass index. Age groups $<40$ years: Common carotid artery (CCA) ........................; brachial artery (BA) ........... $\square \ldots \ldots \ldots \ldots . ;$ femoral artery (FA) .......... $\triangleright \ldots \ldots \ldots . . ; \geq 40$ years: $\mathrm{CCA} \longrightarrow ; \mathrm{BA} \longrightarrow$ _

There was no heterogeneity between women and men in the relationship of arterial diameter or distensibility with BMI $(0.17<P<0.92)$. The latter measurement incorporates weight and height. In a further analysis (Fig. 3), we therefore pooled the two sexes and we replaced in the multiple regression models BMI by weight and height. Arterial diameter and distensibility were significantly $(P<0.008)$ associated with body weight as well as body height in the three vascular

Fig. 2

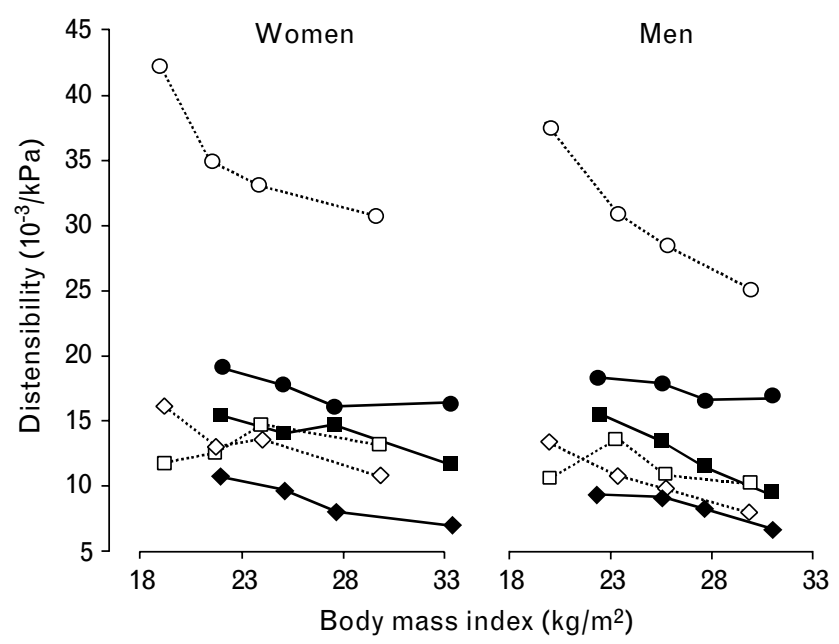

Arterial distensibility by sex and vascular territory. Plotted values are means in sex and age group-specific quartiles of body mass index. Age groups < 40 years: Common carotid artery (CCA) ........................; brachial artery (BA) ............ $\square \ldots \ldots \ldots \ldots . .$. ; femoral artery (FA) ...................... ; $\geq 40$ years: $\mathrm{CCA} \longrightarrow$ _ 
Table 3 Partial regression coefficients between vessel wall properties and body mass index by sex

\begin{tabular}{|c|c|c|c|c|c|c|}
\hline \multirow[b]{2}{*}{ Measurement } & \multicolumn{3}{|c|}{ Women $(n=660)$} & \multicolumn{3}{|c|}{$\operatorname{Men}(n=646)$} \\
\hline & Coefficient \pm SE & $P$ & $P_{\text {int }}$ & Coefficient \pm SE & $P$ & $P_{\text {int }}$ \\
\hline Carotid-femoral PWV $(\mathrm{m} / \mathrm{s})$ & $0.038 \pm 0.016$ & 0.02 & 0.14 & $-0.011 \pm 0.021$ & 0.58 & 0.16 \\
\hline \multicolumn{7}{|l|}{ Common carotid artery } \\
\hline Diameter $(\mathrm{mm})$ & $0.020 \pm 0.006$ & 0.0006 & 0.004 & $0.051 \pm 0.008$ & 0.0001 & 0.08 \\
\hline Distensibility $\left(10^{-3} / \mathrm{kPa}\right)$ & $-0.172 \pm 0.078$ & 0.027 & 0.0001 & $-0.372 \pm 0.097$ & 0.0001 & 0.001 \\
\hline \multicolumn{7}{|l|}{ Brachial artery } \\
\hline Diameter $(\mathrm{mm})$ & $0.022 \pm 0.005$ & 0.0001 & 0.07 & $0.054 \pm 0.009$ & 0.0001 & 0.79 \\
\hline Distensibility $\left(10^{-3} / \mathrm{kPa}\right)$ & $-0.156 \pm 0.069$ & 0.02 & 0.49 & $-0.329 \pm 0.077$ & 0.0001 & 0.57 \\
\hline \multicolumn{7}{|l|}{ Femoral artery } \\
\hline Diameter (mm) & $0.037 \pm 0.009$ & 0.0002 & 0.66 & $0.088 \pm 0.016$ & 0.0001 & 0.07 \\
\hline Distensibility $\left(10^{-3} / \mathrm{kPa}\right)$ & $-0.211 \pm 0.065$ & 0.001 & 0.17 & $-0.245 \pm 0.066$ & 0.0002 & 0.76 \\
\hline
\end{tabular}

PWV, Pulse wave velocity. Regression coefficients were adjusted for observer, age, mean arterial pressure, pulse rate, smoking, alcohol intake, and antihypertensive drug intake. $P$ and $P_{\text {int }}$ refer to the significance of the partial regression coefficient with body mass index and the continuous interaction term between body mass index and age, respectively.

territories, with the exception of the relationship of body height with carotid $(P=0.92)$ and brachial $(P=0.14)$ diameter as well as with brachial $(P=0.19)$ and femoral $(P=0.27)$ distensibility.

\section{Interaction between body mass index and age}

With similar adjustments as before, we explored the interaction between BMI and age using continuous variables (Table 3). These interaction terms were either

Fig. 3
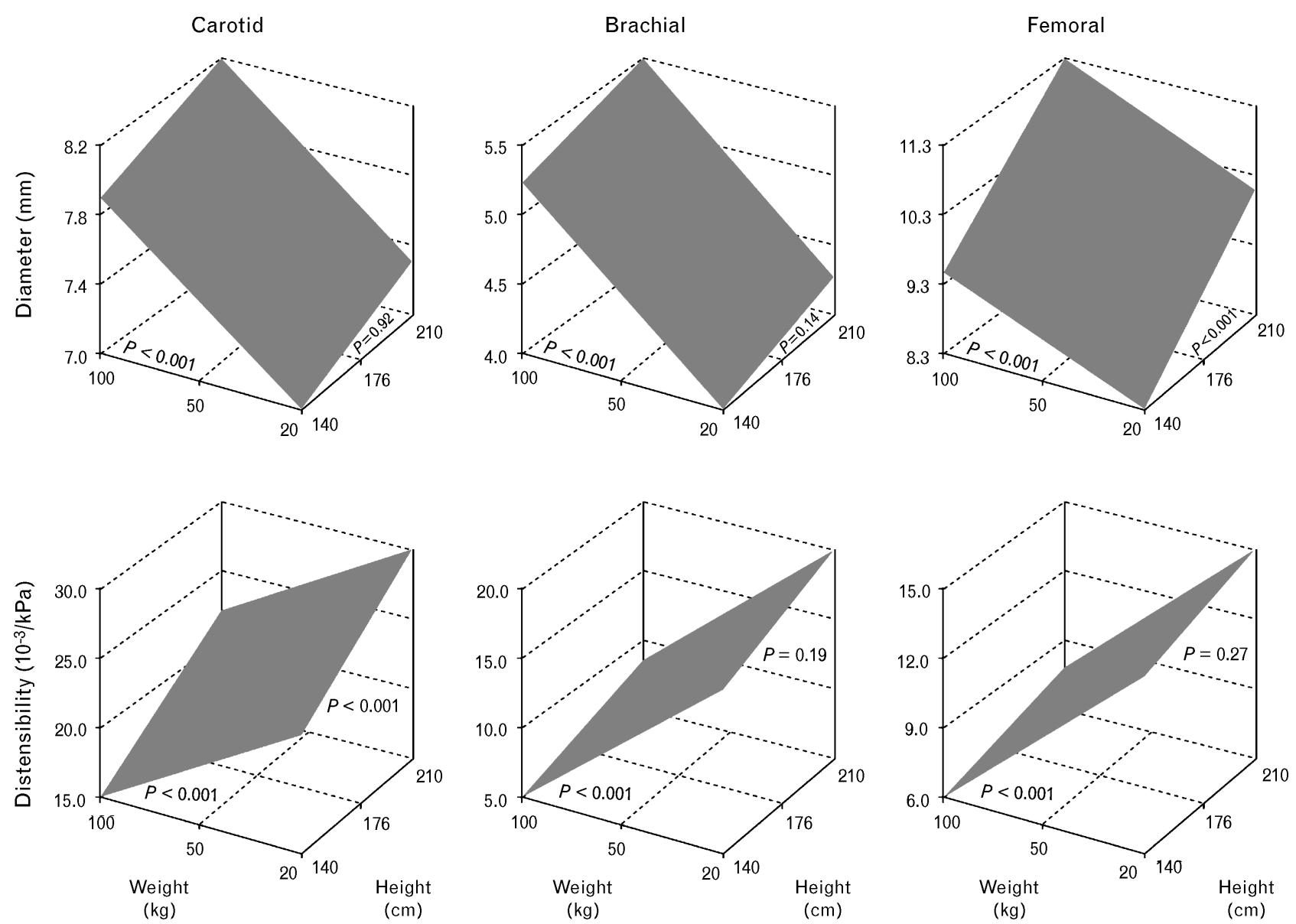

Relationship between arterial characteristics and body weight and height in men and women combined. The relationships were standardized for observer, age, mean arterial pressure, pulse pressure, smoking, alcohol intake, and use of antihypertensive drugs. 
Table 4 Changes in arterial characteristics associated with a 1 SD increase in body mass index at specific ages

\begin{tabular}{|c|c|c|c|}
\hline Measurement & Age & Women & Men \\
\hline \multirow[t]{3}{*}{ Carotid-femoral PWV $(\mathrm{m} / \mathrm{s})$} & 20 & $0.017(-0.203$ to 0.237$)$ & $-0.193(-0.454$ to 0.068$)$ \\
\hline & 40 & $0.140(0.015$ to 0.265$)$ & $-0.053(-0.216$ to 0.110$)$ \\
\hline & 60 & 0.263 (0.073 to 0.453$)$ & $0.087(-0.158$ to 0.332$)$ \\
\hline \multicolumn{4}{|l|}{ Common carotid artery } \\
\hline \multirow[t]{3}{*}{ Diameter $(\mathrm{mm})$} & 20 & $-0.022(-0.036$ to -0.008$)$ & $0.127(0.017$ to 0.237$)$ \\
\hline & 40 & $0.063(0.016$ to 0.110$)$ & $0.194(0.127$ to 0.261$)$ \\
\hline & 60 & 0.148 (0.083 to 0.213$)$ & $0.262(0.172$ to 0.352$)$ \\
\hline \multirow[t]{3}{*}{ Distensibility $\left(10^{-3} / \mathrm{kPa}\right)$} & 20 & $-2.623(-3.707$ to -1.539$)$ & $-3.102(-4.335$ to -1.869$)$ \\
\hline & 40 & $-0.980(-1.599$ to -0.361$)$ & $-1.640(-2.397$ to -0.883$)$ \\
\hline & 60 & $0.633(-0.239$ to 1.505$)$ & $-0.178(-1.270$ to 0.914$)$ \\
\hline \multicolumn{4}{|l|}{ Brachial artery } \\
\hline \multirow[t]{3}{*}{ Diameter $(\mathrm{mm})$} & 20 & $0.035(0.034$ to 0.104$)$ & $0.225(0.137$ to 0.313$)$ \\
\hline & 40 & 0.079 (0.040 to 0.118$)$ & $0.217(0.164$ to 0.270$)$ \\
\hline & 60 & $0.123(0.072$ to 0.174$)$ & $0.208(0.135$ to 0.281$)$ \\
\hline \multirow[t]{3}{*}{ Distensibility $\left(10^{-3} / \mathrm{kPa}\right)$} & 20 & $-0.322(-1.341$ to 0.697$)$ & $-1.079(-2.092$ to -0.066$)$ \\
\hline & 40 & $-0.564(-1.134$ to 0.006$)$ & $-1.284(-1.900$ to -0.669$)$ \\
\hline & 60 & $-0.806(-1.551$ to -0.061$)$ & $-1.490(-2.333$ to -0.647$)$ \\
\hline \multicolumn{4}{|l|}{ Femoral artery } \\
\hline \multirow[t]{3}{*}{ Diameter $(\mathrm{mm})$} & 20 & $0.122(-0.013$ to 0.257$)$ & $0.496(0.296$ to 0.696$)$ \\
\hline & 40 & $0.144(0.066$ to 0.222$)$ & $0.362(0.239$ to 0.485$)$ \\
\hline & 60 & $0.166(0.050$ to 0.282$)$ & $0.228(0.044$ to 0.412$)$ \\
\hline \multirow[t]{3}{*}{ Distensibility $\left(10^{-3} / \mathrm{kPa}\right)$} & 20 & $-1.348(-2.228$ to -0.468$)$ & $-1.079(-1.914$ to -0.244$)$ \\
\hline & 40 & $-0.914(-1.429$ to -0.399$)$ & $-0.984(-1.501$ to -0.467$)$ \\
\hline & 60 & $-0.480(-1.205$ to 0.245$)$ & $-0.888(-1.647$ to -0.129$)$ \\
\hline
\end{tabular}

PWV, Pulse wave velocity. Effect sizes (95\% confidence interval) are for an increase in body mass index by $4 \mathrm{~kg} / \mathrm{m}^{2}$ ( 1 SD). Estimates account for the covariance between age and body mass index and for other covariates, including observer, age, mean arterial pressure, pulse rate, smoking, alcohol intake, and antihypertensive drug intake. $P$ values for the continuous interaction term between body mass index and age are presented in Table 3 .

non-significant or of only borderline significance $(0.05$ $<P<0.10)$, except for carotid diameter in women and carotid distensibility in both sexes $(P \leq 0.004)$.

Table 4 provides the predicted effect sizes, which in women and men were associated with an increase in BMI by $4.0 \mathrm{~kg} / \mathrm{m}^{2}(\sim 1 \mathrm{SD})$ at ages 20,40 or 60 years. These adjusted estimates accounted for other covariates and for the interaction and covariance between BMI and age. Brachial and femoral diameter and distensibility changed with BMI in a directionally consistent manner across the whole age range. In men and women, carotid distensibility decreased more with body mass at younger than at older age. In middle-aged and older women, pulse wave velocity increased with higher BMI. In men, the associations between pulse wave velocity and BMI were not significant, irrespective of age.

Neither in women nor men was cross-sectional compliance in any vascular territory significantly and independently correlated with BMI (data not shown). Further cumulative adjustment of the vascular measurements for total and HDL-cholesterol and blood glucose, and in women also for the use of oral contraceptives or hormonal replacement therapy, did not materially alter our results. Analyses with subjects on antihypertensive treatment excluded were also confirmatory.

\section{Discussion}

The key finding of our study was that from 10 to 86 years in women as well as men the diameter and stiffness of the muscular brachial and femoral arteries consistently increased with higher BMI. Age did not significantly impact on the relationship of the characteristics of the muscular arteries with BMI. In contrast, in women and men, stiffening of the carotid artery with BMI was more pronounced at younger than older age. In middle-aged and older women, but not in men of any age, pulse wave velocity increased with higher BMI.

Across three vascular beds and two sexes, at all ages, the arterial lumen consistently increased with higher BMI. In experimental animals and humans, weight gain leads to expansion of the extracellular volume and increases cardiac output and regional blood flow to adipose as well as non-adipose tissues [4,11]. The mechanisms responsible for the increased regional blood flow remain to be elucidated, but must involve the system-wide increased metabolic rate, local accumulation of vasoactive metabolites [12], and the growth of organs and tissues, which have to sustain a larger body with higher metabolic needs. These haemodynamic features, shear stress, increased blood pressure and various nervous and hormonal mechanisms can explain the inverse functional association between arterial distensibility and obesity, which in the long run may lead to structural adaptations in the arteries $[4,13,14]$. We did not find any association between cross-sectional compliance and BMI, possibly because the computation of this vascular index does not account for the diastolic lumen diameter, which was larger in obese than in non-obese individuals.

Among the studies that investigated to what extent adiposity might impact on the properties of large arteries 
[5,6,11,15-26], most had a small sample size (range 16 [22] to 75 [15]; median, 46 [16]) with a case-control design involving obese and non-obese healthy individuals [11,15-17,20-22] or obese and non-obese patients with hypertension [11,19] or type 2 diabetes [25]. Few studies were population based and had sufficient statistical power to allow conclusions with relevant external validity [5,6,18,23,24,26]. Most researchers determined central or peripheral pulse wave velocity $[5,6,18,19$, 23-26]. Other investigators used the ratio of pulse pressure to stroke index [11], the ratio of pulse pressure to the systolic increase in the aortic cross-sectional area [16], or the central systolic augmentation index [22]. Few researchers measured cross-sectional compliance or distensibility at the radial artery [20], the common carotid artery [15], the carotid and femoral arteries [17], or as in the present study at three different arteries [5,21]. By and large, most studies demonstrated that the stiffness of the large arteries increased with various indices of adiposity, including BMI.

Two approaches can shed light on the age at which BMI starts influencing the properties of large arteries. First, some researchers specifically recruited children [27] or young adults $[5,16,17,20,22,23]$ with mean ages ranging from 12.4 [15] to 36.0 [5] years. Among these reports [5,15-17,20,22,23], four studies with a case-control design demonstrated increased arterial stiffness in obese subjects $[15,16,20,22]$. However, in three studies, the continuous relationship between measures of stiffness and obesity were only significant because either obese and non-obese subjects [20,22] or men and women [17] were pooled. In one large study [23], the relationship between pulse wave velocity and BMI did not reach statistical significance. Among the studies in young adults, the report by Ferreira and colleagues [5] stands out. It integrated cross-sectional and prospective findings. It included various indices of obesity and the bodily distribution of fat tissue as well as comprehensive measurements of the arterial properties in the same four vascular territories as in the present study. Ferreira and colleagues [5] found that truncal subcutaneous fat accumulation in adolescents was an independent predictor of increased vascular stiffness at age 36 years. Moreover, at age 36 years, arterial stiffness was positively and independently associated with the amount of abdominal and truncal subcutaneous fat.

Recruitment of study participants with a wide age range, as in the present study, constitutes a second approach, which allows an investigation of the age dependency of the association between arterial properties and adiposity. Among the population-based studies with an appropriate age range [6,24,26], only Wildman and coworkers [6] expanded their analyses along these lines. Pulse wave velocity strongly correlated with higher body weight, BMI and the waist-to-hip ratio, independent of age, sex, race and systolic blood pressure. Even among young adults with an age range from 20 to 30 years, subjects with a BMI exceeding $30 \mathrm{~kg} / \mathrm{m}^{2}$ had a mean aortic pulse wave velocity that was $0.047 \mathrm{~m} / \mathrm{s}$ higher than in their non-obese counterparts. The analysis of Wildman et al. [6] was not stratified for sex.

In the present study, BMI was a significant and independent determinant of pulse wave velocity in women, but not in men. In 521 healthy participants of the Framingham Heart Study with mean age of 56.6 years $(63.9 \%$ women), neither carotid-femoral nor carotid-brachial pulse wave velocity were related to BMI [24]. This was also the case in 2431 Japanese men (aged 35-54 years) [26] and 524 Dutch men and women (aged 27-30 years) [23]. The Framingham investigators excluded obese $\left(\geq 30 \mathrm{~kg} / \mathrm{m}^{2}\right)$ individuals from their analysis. BMI in the Japanese [26] and Dutch [23] studies averaged only 23.4 and $24.5 \mathrm{~kg} / \mathrm{m}^{2}$, respectively. Nevertheless, our population study and at least three others $[23,24,26]$ suggest that the age-adjusted relationship between aortic stiffness and adiposity might be weaker than for peripheral arteries. Obesity in men is more centrally located than in women. An overestimation of the length of the carotid-femoral segment can artificially inflate the measurement of aortic pulse wave velocity. However, such artefact would strengthen rather than weaken the correlations with BMI. Two other mechanisms are probably more plausible to explain the weak relationship between aortic pulse wave velocity and BMI. First, BMI explains up to $30 \%$ of the blood pressure variability in the general population. Pulse wave velocity is measured independently of blood pressure, whereas the computation of arterial distensibility involves blood pressure. Second, BMI is an imprecise measure of adiposity. In 2488 older adults with a mean age of 74 years (52.3\% women) enrolled in the Study of Health, Aging and Body Composition [18], the researchers used computed tomography to measure abdominal visceral fat. In that population-based study, the investigators noticed in all subjects and even in thirds of the distribution of body weight a strong association between aortic pulse wave velocity and abdominal visceral fat, which was independent of body weight, whereas the association between pulse wave velocity and body weight was not significant when controlling for other covariates [18].

The present study has to be interpreted within the context of its limitations and strengths. We did not assess body fatness and its distribution by means of sophisticated techniques, such as dual energy X-ray absorptiometry $[5,18,25]$ or computed tomography $[18,25]$, but as most other researchers, we estimated adiposity from simple anthropometric measurements. We applied a cross-sectional design to investigate the influence of age on the relationship between vascular stiffness and obesity. We cannot exclude the possibility that cohort 
effects or secular trends over the observation period (1999-2003) confounded our results. Most subjects were examined in a non-fasting state. The requested 3-h interval of abstinence from drinking alcoholic or caffeine-containing beverages or heavy exercise might not have been long enough to standardize the vascular measurements fully. We did not collect information on obstructive sleep apnoea, which is common among obese individuals and which itself might affect cardiac and vascular function [3]. The prevalence of sleep apnoea in middle-aged American and western European populations is approximately $20 \%$, which is less than the prevalence of overweight and obesity. Approximately $40 \%$ of obese individuals experience sleep apnoea [28]. Obstruction of the airways during sleep might therefore have been a confounder in the presently reported associations between the arterial properties and BMI. On the other hand, sleep-related breathing disorders lead to an increase in mean arterial pressure, but not pulse pressure [29].

Only three highly trained specialists measured the arterial properties in four different arterial territories by means of an ultrasound technique, which in experienced hands has high intraobserver and interobserver reproducibility within and across sessions [21,30]. We implemented a quality control programme to minimize measurement error in the blood pressure readings, which more readily occurs in obese individuals with a large arm circumference [8]. Our representative population sample was large enough to allow stratification for sex and had a wide age range. Sensitivity analyses, which accounted for antihypertensive drug treatment, serum cholesterol and blood glucose or the use of oral contraceptives or hormonal replacement therapy, were confirmatory. In comparison with two previous key reports with a similar focus [5,6], our study adds new information, because it had a substantially larger sample size allowing us to analyse men and women separately. In comparison to the study by Wildman et al. [6], we studied three additional arterial territories and we analysed the interaction between age and BMI without dichotomization of the distributions.

We demonstrated that already from a young age onwards, the diameter of large arteries and the stiffness of muscular arteries increases with higher BMI. In elastic arteries, the relationship between arterial stiffness and BMI seems to be modulated by sex and age. The mechanisms underlying the apparent differences in the associations of BMI with the properties of vascular as compared with elastic arteries need further clarification. Because among youth obesity is becoming a global problem, and because increased vascular stiffness is a forerunner of cardiovascular complications, our findings highlight the potential for prevention at a young age. Preliminary evidence from a small intervention study [31] suggested that in young adults weight loss augments carotid distensibility probably because of the decrease in blood pressure, but the generalizability of this conclusion to any type of artery remains to be proved, especially in children and adolescents.

\section{Acknowledgements}

The Flemish population study would not have been possible without the collaboration of the family physicians of the participants. The municipality HechtelEksel (Belgium) gave logistic support. H. Celis T. Kuznetsova, Yan Li, and Ji-Guang Wang helped cleaning the database. The authors acknowledge the expert assistance of R. Bollen, S. Covens, L. Gijsbers, M.J. Jehoul, H. Truyens, S. Van Hulle, and R. Wolfs (Study Coordinating Centre, Leuven, Belgium).

\section{References}

1 World Health Organization. The problem of overweight and obesity. In: Obesity: preventing and managing the global epidemic. Report of a WHO Consultation. Geneva, Switzerland: World Health Organization; 1997. pp. 5-37.

2 Flegal KM, Carroll MD, Ogden CL, Johnson CL. Prevalence and trends in obesity among US adults, 1999-2000. JAMA 2002; 288:1723-1727.

3 Jelic S, Bartels MN, Mateika JH, Ngai P, DeMeersman RE, Basner RC. Arterial stiffness increases during obstructive sleep apneas. Sleep 2002; 25:850-855.

4 Hall JE. The kidney, hypertension, and obesity. Hypertension 2003; 41:625-633.

5 Ferreira I, Twisk JWR, van Mechelen W, Kemper HCG, Seidell JC, Stehouwer CDA. Current and adolescent body fatness and fat distribution: relationship with carotid intima-media thickness and large artery stiffness at the age of 36 years. J Hypertens 2004; 22:145-155.

6 Wildman RP, Mackey RH, Bostom A, Thompson T, Sutton-Tyrrell K. Measures of obesity are associated with vascular stiffness in young and older adults. Hypertension 2003; 42:468-473.

7 Balkestein EJ, Staessen JA, Wang JG, van der Heijden-Spek JJ, Van Bortel $\mathrm{L}$, Barlassina C, et al. Carotid and femoral artery stiffness in relation to three candidate genes in a white population. Hypertension 2001; 38:1190-1197.

8 Kuznetsova T, Staessen JA, Kawecka-Jaszcz K, Babeanu S, Casiglia E, Filipovský J, et al. Quality control of the blood pressure phenotype in the European Project on Genes in Hypertension. Blood Press Monit 2002; 7:215-224.

9 Van Bortel LM, Balkestein EJ, van der Heijden-Spek JJ, Vanmolkot FH, Staessen JA, Kragten JA, et al. Non-invasive assessment of local arterial pulse pressure: comparison of applanation tonometry and echo-tracking. $J$ Hypertens 2001 ; 19:1037-1044.

10 Hoeks APG, Reneman RS. Biophysical principles of vascular diagnosis. $J$ Clin Ultrasound 1995; 23:71-79.

11 Oren S, Grossman E, Frohlich ED. Arterial and venous compliance in obese and nonobese subjects. Am J Cardiol 1996; 77:665-667.

12 Ardilouze JL, Fielding BA, Currie JM, Frayn KN, Karpe F. Nitric oxide and $\beta$-adrenergic stimulation are major regulators of preprandial and postprandial subcutaneous adipose tissue blood flow in humans. Circulation 2004; 109:47-52.

13 Singhal A, Farooqi IS, Cole TJ, O'Rahilly S, Fewtrell M, Kattenhorn M, et al. Influence of leptin on arterial distensibility. A novel link between obesity and cardiovascular disease? Circulation 2002; 106:1919-1924.

14 Verlohren S, Dubrovska G, Tsang SY, Essin K, Luft FC, Huang Y, et al. Visceral periadventitial adipose tissue regulates arterial tone of mesenteric arteries. Hypertension 2004; 44:271-276.

15 Tounian P, Aggoun Y, Dubern B, Varille V, Guy-Grand B, Sidi D, et al. Presence of increased stiffness of the common carotid artery and endothelial dysfunction in severely obese children. Lancet 2001 ; 358:1400-1404.

16 Danias PG, Tritos NA, Stuber M, Botnar RM, Kissinger KV, Manning WJ. Comparison of aortic elasticity determined by cardiovascular magnetic resonance imaging in obese versus lean adults. Am J Cardio/ 2003; 91:195-199.

17 Giltay EJ, Lambert J, Elbers JMH, Gooren LJG, Asscheman H, Stehouwer CDA. Arterial compliance and distensibility are modulated by body composition in both men and women but by insulin sensitivity only in women. Diabetologia 1999; 42:214-221. 
18 Sutton-Tyrrell K, Newman A, Simonsick EM, Havlik R, Pahor M, Lakatta E, et al. Aortic stiffness is associated with visceral adiposity in older adults enrolled in the Study of Health, Aging, and Body Composition. Hypertension 2001; 38:429-433.

19 Toto-Moukouo JJ, Achimastos A, Asmar RG, Hugues CJ, Safar ME. Pulse wave velocity in patients with obesity and hypertension. Am Heart J 1986 112:136-140.

20 Mangoni AA, Giannattasio C, Brunani A, Failla M, Colombo M, Bolla G, et al. Radial artery compliance in young, obese, normotensive subjects. Hypertension 1995; 26:984-988.

21 Spek JJ, Hoeks APG, Struijker-Boudier HAJ, Van Bortel LMAB. Differences in vessel wall properties of large arteries between obese and lean subjects. Nier und Hochdrukkrankheiten 1995; 8:431-432.

22 Westerbacka J, Vehkavaara S, Bergholm R, Wilkinson I, Yki-Järvinen H. Marked resistance of the ability of insulin decrease arterial stiffness characterizes human obesity. Diabetes 1999; 48:821-827.

23 Oren A, Vos LE, Uiterwaal CSPM, Grobbee DE, Bots ML. Aortic stiffness and carotid intima-media thickness: two independent markers of subclinical vascular damage in young adults? Eur J Clin Invest 2003; 33:949954.

24 Mitchell GF, Parise H, Benjamin EJ, Larson MG, Keyes MJ, Vita JA, et al. Changes in arterial stiffness and wave reflection with advancing age in healthy men and women. The Framingham Heart Study. Hypertension 2004; 43:1239-1245

25 Hegazi RA, Sutton-Tyrrell K, Evans RW, Kuller LH, Belle S, Yamamoto M, et al. Relationship of adiposity to subclinical atherosclerosis in obese patients with type 2 diabetes. Obes Res 2003; 11:1597-1605.

26 Nakanishi N, Suzuki K, Tatara K. Clustered features of the metabolic syndrome and the risk for increased aortic pulse wave velocity in middle-aged Japanese men. Angiology 2003; 54:551-559.

27 Diamantopoulos EJ, Andreadis EA, Vassilopoulos CV, Vlachonikolis IG, Tarassi KE, Chatzis NA, et al. Association of specific HLA phenotypes with left ventricular mass and carotid intima-media thickness in hypertensives. Am J Hypertens 2001; 14:632-636.

28 Young T, Peppard PE, Gottlieb DJ. Epidemiology of obstructive sleep apnea. A population health perspective. Am J Respir Crit Care Med 2002 165:1217-1239.

29 Grote L, Hedner J, Peter JH. Mean blood pressure, pulse pressure and grade of hypertension in untreated hypertensive patients with sleep-related disorder. J Hypertens 2001; 19:683-690.

30 Kool MJF, Van Merode T, Reneman RS, Hoeks APG, Struijker Boudier HAJ, Van Bortel LMAB. Evaluation of the reproducibility of a vessel wall movement detector system for assessment of large artery properties. Cardiovasc Res 1994; 28:610-614.

31 Balkestein EJ, van Aggel-Leijssen DP, van Baak MA, Struijker-Boudier HA Van Bortel LM. The effect of weight loss with or without exercise training on large artery compliance in healthy obese men. J Hypertens 1999; 17:1831-1835 